\title{
VIABILIDAD DEL VIBRIO CHOLERAE O1 EN EL MEDIO DE TRANSPORTE DE CARY-BLAIR.
}

\author{
Elizabeth Castañeda*, Clara Inés de Vargas*.
}

\begin{abstract}
Durante la actual epidemia de cólera en nuestro país, decidimos investigar la viabilidad del Vibrio cholera 01 en el medio de transporte Cary-Blair, el cual fue seleccionado como el medio para el envío de las muestras de materia fecal, siguiendo las recomendaciones de la OMS. La viabilidad fue determinada en 53 muestras las cuales se mantuvieron a temperatura ambiente $\left(23^{\circ} \mathrm{C} \pm 2\right)$, durante seis semanas, realizando subcultivos semanales. La recuperación de $\mathbf{V}$. cholerae 01 fue del $94 \%$ la primera semana y del $89 \%, 87 \%$, $83 \%, 81 \%$ y $72 \%$ las semanas siguientes. La recuperación fue también directamente dependiente de la calidad de la muestra. Nuestros resultados nos permiten concluir que el medio de Cary-Blair es ideal para el envío de este tipo de muestras al laboratorio.
\end{abstract}

\section{INTRODUCCION}

El medio de Stuart, descrito por Moffet, Young y Stuart en 1948, fue el primer medio ampliamente utilizado para el transporte de las muestras clínicas al laboratorio, inicialmente fue empleado para el transporte de las muestras en las que se pretendía aislar Neisseria gonorrhoeae (1); más tarde Stuart al observar en algunas de las muestras el sobrecrecimiento de organismos coliformes, modificó el medio adicionándole un antibiótico el cual no afectaba la viabilidad de la N. gonorrhoeae (2). Posteriormente, Sylvia Cary y Eugene Blair utilizaron el medio de Stuart para el transporte de muestras de materia fecal en las cuales deseaban aislar Shigella, pero también encontraron que había sobrecrecimiento de las enterobacterias no patógenas; ellos concluyeron que los contaminantes derivaban la energía del glicerofosfato que contenía el medio por lo tanto, lo sustituyeron con unas sales inorgánicas, que permitieron tener un medio limitado en nutrientes, con un potencial de oxido-reducción bajo y un pH alto; estas características permitieron aumentar la viabilidad de los germenes patógenos entéricos $(1,2)$.
Varios ensayos han sido realizados para determinar la viabilidad de especies de Shigella y de Salmonella en este nuevo medio, comparándolo con el medio de Stuart; los resultados demostraron que los dos patógenos se mantuvieron viables en el nuevo medio por 49 y 62 días respectivamente, mientras en el Stuart, a los 18 días no se pudieron recuperar $(1,3)$. También se han realizado ensayos comparandolos aislamientos, a partir de muestras clínicas paralelas, utilizando la nueva fórmula de CaryBlair y el caldo de Selenito enriquecido y se encontró mayor frecuencia de aislamientos en las muestras transportadas en el medio de Cary-Blair (2).

En un estudio realizado en 1971 se encontró que en las muestras clínicas transportadas en Cary-Blair, Vibrio parahaemolyticus permanecía viable por 35 días, lo que hizo se considerara como un medio de transporte excelente para muestras fecales y estudios epidemiológicos (4). Las características del medio y el mantener la viabilidad del V.cholerae hasta por 4 semanas, han determinado que sea el medio recomendado por la Organización Mundial de la Salud (OMS), para el transporte

* Grupo de Microbiología del Instituto Nacional de Salud 
de las muestras de materia fecal al laboratorio con el fin de realizar el diagnóstico bacteriológico del cólera $(5,6)$.

En la actual epidemia de cólera en nuestro país, el medio Cary-Blair ha sido ampliamente utilizado para el transporte de las muestras, por ese motivo quisimos determinar, en nuestras condiciones, la viabilidad de $\mathbf{V}$. cholerae O1 en un grupo de muestras enviadas de diferentes regiones del país, para poder asegurar la garantía de calidad en el diagnóstico microbiológico.

\section{MATERIALES Y METODOS}

Muestras. Se emplearon 53 muestras, procedentes de diferentes regiones del país, remitidas en el medio de Cary-Blair, en estas muestras se había aislado e identificado, en nuestro laboratorio, v. cholerae 01 por las técnicas estandarizadas $(6,7)$.

Procedimiento. Las muestras fueron conservadas en el medio de transporte a temperatura ambiente $\left(23^{\circ} \mathrm{C} \pm 2\right)$ durante seis semanas. Semanalmente, las muestras fueron enriquecidas en agua peptonada alcalina pH 8,6 incubadas a $37^{\circ} \mathrm{C}$ durante 6 horas y posteriormente sembradas por agotamiento (semicuantificación) en el agar selectivo TCBS (6,7); las cajas se incubaron en aerobiosis a $37^{\circ} \mathrm{C}$ y la lectura se realizó a las 24 horas, determinándose el crecimiento de las colonias fermentadoras de sacarosa, en cada uno de los cuadrantes.

\section{RESULTADOS}

La recuperación de $\mathbf{v}$. cholerae $\mathrm{O} 1$ fue del $94 \%$ en la primera semana y del $72 \%$ en la sexta con las variaciones semanales observadas en la figura 1.

En la tabla 1 anotamos la correlación entre el número de microorganismos existentes en la muestra inicial, semicuantificados por el crecimiento en cuadrantes y la viabilidad a la sexta semana; esta viabilidad fue del $100 \%$ en las muestras que tenían crecimiento en los cuatro cuadrantes en la muestra inicial.

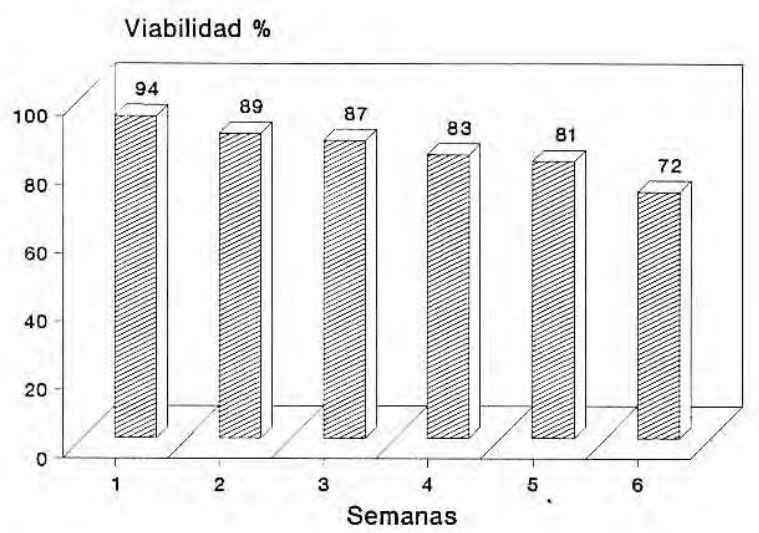

Figura 1. Viabilidad del Vibrio cholerae 01 en el medio de transporte de Cary-Blair, durante las seis semanas de observación.

TABLA 1.

Correlación entre el número de organismos existentes en la muestra inicial (semicuantificación) y la viabilidad a la sexta semana.

\begin{tabular}{cccc}
\hline $\begin{array}{l}\text { Crecimiento } \\
\text { inicial } \\
\text { (cuadrantes) }\end{array}$ & $\begin{array}{l}\text { número } \\
\text { de cepas }\end{array}$ & $\begin{array}{l}\text { viabilidad } \\
\text { n/total }\end{array}$ & $(\%)$ \\
\hline 4 & 5 & $5 / 5$ & $(100)$ \\
3 & 21 & $19 / 21$ & $(90)$ \\
2 & 21 & $16 / 21$ & $(76)$ \\
1 & 6 & $0 / 6$ & $(0)$ \\
\hline
\end{tabular}

\section{DISCUSION}

Los resultados obtenidos confirmaron que el medio de Cary-Blair es adecuado para el transporte de las muestras de materia fecal, para investigar V. cholerae $\mathbf{0 1}$. La viabilidad en nuestras condiciones fue mayor que la descrita en la literatura (7), pero similar a la encontrada para otros enteropatógenos como Shigella y Salmonella (1,2). Estos hallazgos nos garantizan la calidad del transporte de una muestra adecuada, no obstante las demoras en el envío debidas a las deficiencias en los sistemas de 
comunicación. Tal como ocurre en nuestro país, estas epidemias se presentan en regiones con escasos recursos económicos donde los hospitales o centros de salud carecen de un laboratorio adecuado para realizar el diagnóstico etiológico en las muestras iniciales, única forma de detectar la entrada de $\mathbf{V}$. cholerae 01 en una región, por lo tanto se hace necesario el envío de las muestras a un laboratorio de referencia (5).

En la literatura se menciona que el medio es muy estable, si se almacena adecuadamente, conservando sus propiedades después de 19 meses de preparado, eliminando, de esta forma, la necesidad de remplazarlo frecuentemente, 10 que disminuye considerablemente los costos (8). Esta ventaja, y el no requerir refrigeración de la muestra para el envío fueron dos características adicionales del medio empleado para el transporte de las muestras en la epidemia en nuestro país.

La concentración de bacterias en la muestra inicial fue otro factor que determinó la viabilidad del microorganismo, lo que garantiza la recuperación del germen en la fase aguda de la enfermedad, momento en que el paciente excreta el mayor número de microorganismos (5); esta observación se ha realizado con otros enteropatógenos (3).

Nuestros resultados nos permitieron confirmar la utilidad del medio de Cary-Blair como medio de transporte para el envío de muestras al laboratorio de referencia.

\section{SUMMARY}

During the recent outbreak of cholera in Colombia we tried to established the survival time of Vibrio cholera 01 in Cary-Blair transport medium. The viability was determined during six weeks, in 53 samples kept in the laboratory at room temperature $\left(23^{\circ} \mathrm{C} \pm 2\right)$ The recovery was $94 \%$ in the first week, and $89 \%, 87 \%, 83 \%$,
$81 \%$ respectively in the second, third, fourth and fifth weeks and $72 \%$ in the sixth week. Additionally, the recovery of $\mathrm{V}$. cholerae $\mathrm{O} 1$ was directly dependent upon the amount of microorganisms present in the stool sample. Our results allowed us to select Cary-Blair transport medium as an ideal one for shipping samples to the reference center.

\section{AGRADECIMIENTOS}

A la bacterióloga Marcela Escalante por su colaboración en el procesamiento de las muestras.

\section{REFERENCIAS}

1. Cary SG, Blair EB. New transport medium for shipment of clinical specimens.I. Fecal specimens. J Bacteriol 1964; 88: 96.

2. Gaines $\mathbf{S}$, Ul-Haque S, Paniom W, et al. A field trial of a new transport medium for collection of feces for bacteriologic examination. Am I Trop Med Hyg 1965; 14 : 136.

3. Cary SG, Fusillo MH, Harkins C. Survival of Shigella and in a new transport medium. Am J Clin Pathol 1965;43: 294.

4. Neumann DA, Benenson MW, Hubster E, Thi Nhu Tuan N. Cary-Blair, a transport medium for Vibrio parahemolyticus. Am J Clinical Pathol 1971; 57: 33.

5. WHO. Programme for Control of Diarrhoeal Disease. Guidelines for cholera control.1986: WHO/CDD/SER 80.4 REV.1.

6. Farmer JJ, Hickman FW, Kelly MT. VIBRIO. In: Manual of Clinical Microbiology. Fourth Edition. Lennette EH, Balows A, Hausler WJ, Shadomy HJ (eds.). American Society for Microbiology. Washington D.C. 1985 pp 282.

7. Restrepo M, Castañeda E, Rivas F, et al. Cólera. Serie de Notas e Informes Técnicos No 19. Instituto Nacional de Salud, Bogotá 1991.

8. Morris GK, Heck J. Quality of Cary-Blair transport medium after aging nineteen months. J Clin Microbiol $1978 ; 8: 616$ 